\title{
CONSIDERAÇÕES SOBRE A CATALOGAÇÃO DE CERVEJAS ARTESANAIS
}

\author{
Rhanna Henriques Guimarães da Silva \\ Bacharel em Biblioteconomia \\ rhanna_100@hotmail.com \\ Naira Christofoletti Silveira \\ Doutora em Ciência da Informação \\ Docente na Universidade do Estado do Rio de Janeiro (UNIRIO). \\ naira.silveira@unirio.br
}

\section{Resumo}

\begin{abstract}
A pesquisa centra-se na proposta de uma descrição padronizada para cervejas artesanais de modo que essa descrição facilite a organização, o acesso e a recuperação do material cerveja pelos estudiosos, comerciantes e consumidores. Buscou-se, como objetivo geral, identificar os elementos descritivos para a elaboração de uma descrição das cervejas, com base nos princípios e fundamentos da Biblioteconomia, especialmente da Catalogação focado na representação descritiva. Com abordagem qualitativa, adotou-se o método exploratóriodescritivo e a pesquisa bibliográfica e documental. Analisou-se a teoria e os instrumentos da organização e representação da informação. A coleta de dados concentrou-se nas cervejas artesanais cariocas, em seus contêineres, e em informações disponíveis nos site das cervejarias. Procedeu-se a leitura técnica documental, sob a perspectiva cervejeira, do site da cervejaria e dos instrumentos de catalogação, elaborou-se metadados a partir dos elementos identificados, e recorreu-se à análise comparativa dos metadados indicados para a validação. Reafirmou-se, nos resultados, a necessidade de se conhecer as demandas informacionais do público a que se destina a descrição e, mais ainda, o conhecimento técnico especializado do documento e dos instrumentos de representação.
\end{abstract}

Palavras-chave: Catalogação. Cerveja Artesanal. Cerveja Artesanal Carioca. Representação Descritiva.

\section{INTRODUÇÃO}

Neste trabalho, será abordada a catalogação de cervejas artesanais, utilizando da representação descritiva. Segundo Beaumont e Webb (2014), entende-se por cerveja artesanal uma bebida oriunda da fermentação alcoólica da mistura de água e cereal maltado moído (mosto cervejeiro) e lúpulo, produzida em pequena escala, de forma artesanal.

Apesar de se poder contar com os sites de cervejeiros e cervejarias, e de blogs que tratam sobre cerveja artesanal, as informações estão dispersas e não seguem um padrão tanto na definição do conjunto de informações que descrevem os objetos quanto na forma de recuperação.

Por isso descrever cervejas artesanais mostrou-se um desafio dada a especificidade e diversidade do objeto e, mais ainda, por considerar um estudo de metadados que atendesse às particularidades da recuperação da informação por consumidores e cervejeiros. Logo a relevância da pesquisa concentra-se em esforços para o desenvolvimento de uma proposta de descrição padronizada para a cerveja artesanal que possibilite a organização, o acesso e a recuperação do material cerveja pelos estudiosos, comerciantes e consumidores.

Como objetivo geral tem-se: identificar os elementos descritivos para a elaboração de um modelo de descrição para cervejas artesanais, com base nos princípios e fundamentos da Biblioteconomia, especialmente da Catalogação, compreendida aqui como sendo Representação Descritiva e Representação Temática. Para tal, têm-se os seguintes objetivos específicos: a) elencar os elementos presentes na representação bibliográfica 
tradicional; b) identificar quais elementos são necessários para se representar uma cerveja; c) propor uma série de elementos descritivos, com base na Biblioteconomia e na Representação descritiva, para a representação de cervejas em catálogos.

Como a descrição do produto no mercado artesanal ainda é muito simples e inconsistente, acredita-se que este estudo ampliará a atuação do bibliotecário, pois evidenciará que a representação e descrição da informação pode ser realizada sobre qualquer tipo de suporte ou objeto.

\section{CONHECENDO UM POUCO SOBRE A CERVEJA}

A cerveja é uma bebida alcoólica fermentada feita de água, malte, lúpulo e fermento, podendo conter ingredientes adicionais, como frutas e especiarias. Essa é a terceira bebida mais popular do mundo, depois da água e do chá. Existem três tipos principais de cerveja: as Ales, as Lagers e as Lambics. As três diferem em cor, sabor e aroma devido a diferença nos tipos de fermento utilizados para fazer a bebida (ÖHLANDER, 2015).

Segundo o Brewers Association (2015) e o Beer Judge Certification Program (2015), existem diversos estilos de cerveja, os mais comuns de serem encontrados em mercados são, por exemplo: Pilsen; Lager; Weiss; Stout, Índia Pale Ale; Witbier. Esses estilos surgiram através das mudanças que ocorreram na produção da cerveja ao longo do tempo.

As primeiras cervejas surgiram há mais de 10000 anos nas terras férteis da Mesopotâmia entre os rios Tigre e Eufrates. Descobriram que esquecendo a massa de pão encharcada ou os cereais úmidos em algum recipiente aberto ele produziria um líquido açucarado que fermentava com as leveduras (fermento) contidas no ar, produzindo assim uma bebida alcoólica, uma espécie de cerveja (BELTRAMELLI; ÖHLANDER, 2015).

Durante os anos 800-1000 d.C., na era Viking, a cerveja era considerada uma bebida importante para os países nórdicos pois era uma alternativa mais saudável que a água, que era imprópria para o consumo (ÖHLANDER, 2015).

Nos anos de 1040 d.C. monges cristãos desenvolveram uma moderna tecnologia de produção de cerveja, particularmente no que diz respeito às instalações sanitárias e meticulosamente registrando e refinando as próprias receitas. Os monges também adicionavam lúpulos na cerveja, o que tornava possível a preservação da bebida durante longas viagens (BELTRAMELLI, 2014; ÖHLANDER, 2015).

Em 1516 foi promulgada na Baviera a Lei Reinheitsgebot, também conhecida como a lei de pureza Alemã, que foi estabelecida como garantia de qualidade da cerveja. A lei estabelecia que os cervejeiros só estavam permitidos de usar água, cevada maltada e lúpulo quando produziam cerveja. $\mathrm{O}$ fermento não era conhecido na época, mas foi adicionado à lei assim que descoberto em 1857 pelo químico francês Louis Pasteur que descobriu o papel das leveduras na fermentação (HAMPSON, 2014; HUGUES, 2014; ÖHLANDER, 2015).

Como Hampson (2014) nos informa, em 1977 Michael Jackson, influente autor britânico, publica o World guide to beer (Guia mundial da cerveja), sendo um dos primeiros a divulgar as raras e boas cervejas, além disso, suas aparições na televisão estimulou e ajudou a promover as cervejarias artesanais em todo o mundo.

Segundo Beaumont e Webb (2014, p. 11) a cerveja artesanal é produzida em pequena escala, de forma artesanal, elas seguem a Lei da Pureza Alemã de 1516, que prevê somente a utilização de água, malte, lúpulo e leveduras, sem adição de conservantes e outros produtos químicos. $\mathrm{O}$ período de fermentação e maturação da cerveja artesanal acontece sem pressa, ou seja, não são adicionados produtos químicos para acelerá-lo.

De acordo com a Cervejaria Edelbrau (2012) as cervejas industriais são produzidas em larga escala, feitas visando atingir o maior número de consumidores possível. Normalmente, as cervejarias utilizam em suas receitas apenas $60 \%$ de malte e acrescentam formas de açúcar e outros cereais para diminuir os custos de produção, chegando ao consumidor com um preço relativamente baixo.

Na produção cervejeira os ingredientes são muito importantes, a água vem de fontes naturais. Os grãos mais usados são os de cevada, trigo, aveia e arroz. O lúpulo confere o amargor, aroma e sabor à bebida, ele possui potenciais antibacterianos e de preservação, o 
que mantém a cerveja conservada (MORADO, 2009; ÖHLANDER, 2015).

O fermento é dividido em três categorias: os que produzem cerveja Ale, que fermentam em altas temperaturas; os que produzem a cerveja Lagers e fermentam a baixas temperaturas e as leveduras selvagens que produzem as Lambics, que são cervejas de fermentação espontânea. Embora o fermento a princípio seja adicionado à cerveja para transformar açúcar em álcool, isso também concede o perfil de sabor à cerveja (ÖHLANDER, 2015).

Brewing é o processo de preparação da cerveja que envolve cinco passos principais: maltagem, brassagem, cozimento, fermentação e acondicionamento. $\mathrm{Na}$ Maltagem os grãos são molhados e aquecidos para estimular a germinação, que após alguns dias é interrompida, então esse malte é seco e pode ser torrado de várias formas para apresentar certas características, é nesse momento que se escolhe se quer uma cerveja de torra clara à escura (HAMPSON, 2014; ÖHLANDER, 2015).

Esses grãos são moídos e encaminhados para a Mostura ou Brassagem, onde são misturados com água quente para produzir o mosto, que após descansar por algum tempo é coado. Conforme o mosto (líquido) sai, o grão é lavado com mais água quente para liberar os açúcares finais. Depois esse líquido é fervido, nesse ponto pode ser adicionado o lúpulo, além de alguns adjuntos para conferir sabor a cerveja, como chocolate, café, ervas, especiarias, frutas e etc. (HAMPSON, 2014; ÖHLANDER, 2015).

O mosto é coado para remover os ingredientes sólidos, antes de passar pela serpentina para resfriar rapidamente. $\mathrm{O}$ mosto frio é armazenado no tanque de fermentação, nesse momento deve-se escolher o tipo de levedura a ser utilizada. A temperatura também influencia, se for alta demais o fermento morre; se for baixa, ele leva muito tempo para agir. A levedura se alimenta do açúcar do mosto, produzindo dióxido de carbono, álcool e novas células de levedura (HAMPSON, 2014).

Assim que a fermentação termina, o líquido passa a ser chamado de cerveja verde. A maior parte do fermento é removida, e o líquido é transferido para outro recipiente. O líquido matura e evolui com o tempo, pois ocorre uma fermentação secundária com a levedura restante, é quando os sabores e aromas da cerveja são aperfeiçoados. Depois, a cerveja vai para o acondicionamento, seja um barril, garrafa ou lata. Algumas cervejas são clarificadas, outras não são filtradas, elas também podem ser pasteurizadas ou não (HAMPSON, 2014).

Como apresentado até o momento a cerveja sofreu por várias diversificações em seu processo de produção. $\mathrm{O}$ uso de diferentes tipos, em quantidades variáveis e o momento da adição do fermento, do malte, da água, do lúpulo e dos adjuntos conferem diferentes características a bebida e por consequência a criação de diversos estilos. Essas características são importantes para que o consumidor selecione a cerveja que mais the agrada e o cervejeiro faça o controle do estilo de cerveja que deseja produzir. E por isso que o que a catalogação é uma ferramenta essencial para que essas informações sejam organizadas para serem encontradas e acessadas.

\section{AS FUNÇÕES DA CATALOGAÇÃO}

A função da catalogação, também conhecida como representação bibliográfica que abarca a Representação Descritiva e a Representação Temática, é representar um documento de acordo com suas características intrínsecas e extrínsecas para que o mesmo possa ser localizado e recuperado pelo usuário. Neste trabalho a nossa ênfase fica na Representação Descritiva que necessita ser clara, integra, precisa, lógica e consistente. O registro bibliográfico, nada mais é do que os metadados que descrevem o documento (MEY; SILVEIRA, 2009).

O catálogo para ser considerado eficiente e efetivo deve permitir que se localizasse, identifique, selecione, adquira ou obtenha acesso ao documento que atenda as suas necessidades. Ele é um espelho da biblioteca, pois representa seu acervo e sua organização e ajuda os usuários a encontrarem o documento desejado e ainda abre portas para que eles encontrem outros documentos relacionados à sua área de interesse. Os elementos descritivos devem ser padronizados e utilizar um conjunto comum de regras para que facilite a integração, o compartilhamento e a própria descrição dos materiais (MEY; SILVEIRA, 2009; IFLA, 2009). 
Devido ao esforço conjunto da American Library Association (ALA) e a Library Association, no Reino Unido, surgiu um conjunto de regras para a descrição bibliográfica, que resultou no código mais conhecido e utilizado de catalogação: o AngloAmerican cataloguing rules (AACR). No ano de 1969 a International Federation of Library Associations (IFLA) organizou a Reunião Internacional de Especialistas em Catalogação que resultou na proposta do estabelecimento de normas internacionais para a forma e conteúdo da descrição bibliográfica, chamada International Standard Bibliographic Description (ISBD) (CAMPELLO, 2006).

A ISBD tem por finalidade principal o fornecimento de uma estrutura internacionalmente aceita para a apresentação da informação descritiva no registro bibliográfico (BARBOSA, 1978).

Bassi (2011) explica que a ficha catalográfica é um registro dos elementos descritivos importantes de um recurso de informação e que servem para selecioná-lo diante de uma necessidade de informação e para localizá-lo fisicamente. E ela é construída aos moldes da ISBD utilizando um código de catalogação, neste caso iremos trabalhar com o Código de catalogação Anglo-Americano, $2^{\mathrm{a}}$ edição, revisão de 2002 (AACR2R), que de acordo com o próprio Código (2002), suas regras foram baseadas na ISBD.

Segundo o Código (2002, p. 1) "as regras do AACR2 destinam-se a elaboração de um catálogo e outras listas em bibliotecas. Incluem a descrição e a provisão de pontos de acesso para todos os materiais.".

O AACR2 ainda aponta que é necessário ressaltar todos os aspectos do item que está sendo descrito, inclusive o seu conteúdo, o seu suporte físico, o tipo de publicação, suas relações bibliográficas, bem como o fato dele ter sido publicado ou não. Em qualquer área da descrição física, todos os aspectos relevantes deveriam ser descritos seguindo uma regra prática, o catalogador deveria aplicar as regras mais especificas ao item que está sendo catalogado sempre que diferirem das regras gerais. O Código (2002) prescreve que uma fonte de informação descritiva pode ser unitária ou coletiva. É aconselhável dar preferência à informação encontrada em qualquer outro lugar.
Cada área de descrição representa um metadado, que segundo Takahashi (2000 apud SANTOS; ZAFALON, 2015, p. 69) metadado é "qualquer dado usado para auxiliar na identificação, descrição e localização da informação." Mais do que elementos descritivos de um recurso, metadados podem incorporar elementos que representem 0 contexto em que ele está inserido, como o tipo do recurso, sua localização, e seu relacionamento com outros recursos. Possuem uma relação direta com o recurso, assim como um livro tem com seu registro em um catálogo de biblioteca (GRÁCIO, 2002). Os metadados e as áreas de descrição podem ser aplicados desde livros a outros suportes, que no caso, este trabalho versa sobre identificar os metadados para descrever as cervejas artesanais.

\section{PROCEDIMENTOS METODOLÓGICOS}

Neste trabalho, no qual o foco são as cervejas artesanais, baseando-se no método de trabalho de Santos e Zafalon (2015), que abordou carrinhos colecionáveis, optou-se por primeiro apresentar o objeto de estudo, a cerveja. Em seguida foram selecionadas 4 cervejas artesanais cariocas divididas em 2 casos

Como não se teve acesso às cervejas em mãos, para a identificação dos elementos a serem considerados na representação, se utilizou o capítulo 10 do Código (2002) sobre Artefatos tridimensionais e realia, que segundo a regra 10.0B1 prescreve que "A fonte principal de informação [...] é o próprio objeto, juntamente com qualquer outro material textual e o contêiner, publicados pelo editor ou pelo fabricante do item." Sendo assim as informações foram colhidas dos rótulos disponibilizados online pelas cervejarias, e das descrições disponíveis nos sites das cervejarias.

Com base nas informações contidas nos rótulos, considerando que essas informações variam de marca para marca, pode-se afirmar que o rótulo apresenta: o nome da cerveja, o nome da cervejaria, o estilo da cerveja, o teor alcóolico (ABV), a capacidade de armazenamento do recipiente (garrafa). Observou-se que nem todos os rótulos apresentam os níveis de IBU, o uso de 
adjuntos. Desse modo, para mais informações deve-se recorrer ao site da cervejaria.

Os sites das cervejarias, no caso a 2 Cabeças, disponibilizam reproduções dos rótulos, a identificação dos elementos sob o ponto de vista do cervejeiro e informações adicionais que não estão presentes nos rótulos. Com base nas informações disponibilizadas no site da 2 cabeças, foram identificados: o histórico da cerveja, o estilo da cerveja, o teor alcóolico, o índice de amargor (IBU), as notas aromáticas, os adjuntos utilizados e o método de adição do adjunto, os tipos de malte e os tipos de lúpulo.

De acordo com a leitura técnica documental feita nos rótulos foram identificados elementos que descrevem o título, a indicação de responsabilidade, o local, elementos de descrição física, e notas de conteúdo. Como são marcas variadas as informações podem variar tendo mais ou menos elementos. Elementos estes que serão analisados na próxima seção.

\section{ANÁLISE DOS DADOS}

Após a coleta de dados, as informações reunidas serão organizadas de acordo com o Código de Catalogação Anglo-Americano, $2^{\mathrm{a}}$ edição, com revisão de 2002 (AACR2R) com o auxílio dos guias de estilo de cerveja do Beer Judge Certification Program (2015) e do Brewers Association (2015). Na seção 5.1 serão relacionados os elementos descritivos da catalogação biblioteconômica e da cerveja artesanal e será criado um modelo para a descrição da bebida. E na seção 5.2 o modelo será aplicado aos dados colhidos sobre as cervejas artesanais.

\subsection{A RELAÇÃO DOS ELEMENTOS DECRITIVOS}

Mediante a natureza do objeto pesquisado e a relevância da adoção de padrões de metadados, optou-se por consultar os elementos estabelecidos para descrição presentes no Código de Catalogação AngloAmericano, $2^{\mathrm{a}}$ edição, com revisão de 2002 (AACR2R), especificamente o capítulo 1, que contemplam as Regras Gerais de Descrição.

De início, justifica-se a escolha do capítulo destinado as Regras Gerais de Descrição, pois ele estabelece regras gerais, para qualquer tipo de material, no caso a cerveja que comumente não é um material catalogado pela Biblioteconomia, este capítulo pode ser facilmente adaptado para as necessidades da descrição deste objeto.

O processo de representação documental se dá a partir da descrição de elementos do objeto, destaca-se a orientação presente na regra 1.0A1, a qual diz para que se "prefira a informação encontrada na fonte principal àquela encontrada em qualquer outro local" (CÓDIGO..., 2002, p. 1-3) e para os itens sem fonte principal de informação utilizar a regra 1.0A2: "se nenhuma parte do item fornecer dados que possam ser usados como base de descrição, tire a informação necessária de qualquer fonte disponível, seja ela uma fonte de referência ou o conteúdo do próprio item" (CÓDIGO..., 2002, p. 1-3). Compreende-se, portanto, que para a descrição das cervejas recorra-se à consulta ao próprio objeto bem como ao site da cervejaria responsável.

Os principais elementos descritivos que permitem a identificação de um documento são indicados na regra 1.0B1 (CÓDIGO..., 2002). Esta regra elenca as áreas de metadados relacionados: ao título e indicação de responsabilidade; à edição; aos detalhes específicos do material; à publicação, distribuição; à descrição física; à série; às notas; ao número normalizado e modalidades de aquisição.

Entretanto, para representar uma cerveja temos de pensar em outros atributos para que tanto o cervejeiro quanto $\mathrm{o}$ consumidor consigam encontrar as informações que os satisfaçam. Características como o nome da cervejaria; o nome da cerveja; a família (Ale, Lager, híbrida) a qual pertence; estilo (pilsen, weizen, lambic, etc.) característico; se ela foi produzida em parceria com alguma outra cervejaria; cor (SRM); notas aromáticas; notas gustativas; amargor (IBU); teor alcóolico (ABV); tipo de malte; tipo de lúpulo; tipo de levedura; tipo de fermentação; adjuntos; região de origem; era de produção (industrial, artesanal, histórica), extraídas dos guias de estilo de cerveja do Beer Judge Certification Program (2015) e do Brewers Association (2015), se presentes em um catálogo, definem a representação da cerveja antes mesmo que $o$ pesquisador tenha contato com a mesma.

Com base nas informações coletadas e nas informações identificadas no Código (2002), 
no Beer Judge Certification Program (2015) e no Brewers Association (2015), ficam estabelecidos os elementos descritos presentes nas alíneas “a)" à “j)", abaixo relacionados, apresentados em forma de discussão sobre os metadados destinados à cerveja artesanal:

a) Título: para o título assume-se o nome da cerveja impresso no rótulo fixado no contêiner do produto ou aquele informado no site da cervejaria.

b) Indicação de responsabilidade: utiliza-se o nome da cervejaria como aparece impresso no rótulo fixado no contêiner do produto, como indicado na regra $1.1 \mathrm{~F} 1$ a qual indica para que se "transcreva a indicação de responsabilidade que figurem com destaque no item na forma em que nele aparecem." (CÓDIGO..., 2002, p. 1-15).

c) Designação geral do material (DGM): de uso opcional, conforme indicação da regra 1.1C.do Código (2002). Como a lista de materiais não abrange o tipo de material catalogado optou-se por usar a descrição cerveja em vez de bebida alcóolica fermentada, respeitando a terminologia usada por cervejeiros e consumidores, como visto na leitura técnica dos rótulos das cervejas e sites das cervejarias. Adiciona-se também a família da cerveja e o estilo. Para terminologias referentes a família e estilo recorrer aos guias de estilo de cerveja do Beer Judge Certification Program (2015) e do Brewers Association (2015).

d) Edição: algumas cervejas são produzidas em edições comemorativas ou em parceria com alguma outra cervejaria, restaurante ou empresa, por isso foi escolhida a regra $1.2 \mathrm{C} 1$. que se refere as indicações de responsabilidade relativas à edição que diz para que se "transcreva uma indicação de responsabilidade relativa a uma ou mais edições [...], depois da indicação de edição, se houver alguma." (CÓDIGO...,2002, p. 1-20).

e) Detalhes específicos do material (ou do tipo de publicação): não será utilizada nesta proposta uma vez que não se enquadra ao material catalogado, conforme indicação da regra $1.3 \mathrm{~A}$.

f) Publicação: registrar neste campo o lugar de produção; o nome do produtor; o distribuidor; a data de produção; o lugar de fabricação; o nome do fabricante, caso seja diferente do produtor usar a regra $1.4 \mathrm{G} 4$ que diz para registrar "o lugar, o nome do fabricante $[\ldots]$ se forem diferentes do [...]" (CÓDIGO...,2002, p. 1-31) lugar de produção e/ou nome do produtor; e a data de fabricação.

g) Descrição física: em extensão do item deve ser indicada a quantidade de unidades físicas do objeto seguido do termo que melhor o designa como indicado na regra 1.5B1. Para a descrição de detalhes físicos recorre-se às regras $1.5 \mathrm{C} 1$. Dado o fato de que a Cor (SRM); a Unidade internacional de amargor (IBU); e o teor alcóolico (ABV), são elementos fundamentais para a recuperação das informações pelo usuário, isso requer a especificidade na descrição unívoca do objeto, optou-se pelo uso dos guias de estilo de cerveja BJCP (2015) e BA (2015) que dentro de suas classificações de estilo, elencam a melhor forma de descrever esses elementos.

Nesta alínea, destinada à descrição física, especificamente sobre a escala de cor, os guias usam o padrão americano Standard Reference Method (SRM) e o padrão European Brewing Convention (EBC) para medição da cor da cerveja, esses padrões medem a intensidade de acordo com o comprimento de onda da luz. Esses valores numéricos nem sempre correspondem a nossa percepção visual de luminosidade, escuridão ou tonalidade. $\mathrm{Na}$ dúvida, a descrição de cor possui prioridade. A tabela do SRM é a mais utilizada e a descrição da cor utiliza a faixa de cor e é atribuído um valor representativo desse comprimento de luz.

Ainda sobre a descrição física, o amargor da cerveja é medido com o International Bitterness Units (IBU) ou Unidade internacional de amargor. O valor numérico é mensurado a partir de um especifico composto de lúpulo e não necessariamente coincide com a percepção individual da intensidade de amargor, esse valor varia de 0 - 120 IBUs (BJCP, 2015).

Para finalizar essa alínea, para o teor alcóolico (ABV) basta seguir a regra 1.5A2. onde diz para retirar "do próprio item a informação indicada [...]." (CÓDIGO...,2002, p. 1-31). Para a indicação das dimensões consultou-se as regras $1.5 \mathrm{D} 1$ e $1.5 \mathrm{D} 2$, a $1.5 \mathrm{D} 2$ diz que "se o item estiver acondicionado em um contêiner, mencione o contêiner e registre suas dimensões, após as dimensões do item [...]" (CÓDIGO...,2002, p. 1-33). 
h) Série: preencher com a série, quando houver.

i) Notas: além das notas já especificadas na área das notas, cabe acrescentar aqui, devido a natureza do material, notas referentes ao tipo de malte (qual cereal usado); o tipo de lúpulo; o tipo de levedura; o tipo de fermentação; os adjuntos; a região de origem da cerveja; e sua era de produção (industrial, artesanal, histórica). j) Número normalizado e modalidades de aquisição: preencher com o código de barras do produto, quando houver.

Com base na análise realizada nas alíneas acima, de A à J, no Quadro 1 segue a relação entre as áreas descritivas presentes no Código (2002) e os elementos importantes para a descrição da cerveja artesanal.

Quadro 1 - Relação entre elementos descritivos

\begin{tabular}{|c|c|c|}
\hline $\begin{array}{l}\text { ÁREAS } \\
\text { DESCRITIVAS DO } \\
\text { CÓDIGO (2002) } \\
\end{array}$ & $\begin{array}{c}\text { Metadados para descrição da cerveja } \\
\text { artesanal }\end{array}$ & $\begin{array}{c}\text { Área De Preenchimento Dos } \\
\text { Metadados }\end{array}$ \\
\hline \multirow{3}{*}{$\begin{array}{l}\text { ÁREA DE TITULO E } \\
\text { INDICAÇÃO DE } \\
\text { RESPONSABILIDADE }\end{array}$} & Título da cerveja & Nome da Cerveja \\
\hline & Designação geral do material & Cerveja: Família: Estilo \\
\hline & Cervejaria responsável & Nome Da Cervejaria \\
\hline \multirow{2}{*}{ ÁREA DA EDIÇÃO } & Indicação de edição & $\begin{array}{c}\text { Edição Comemorativa Ou Feita Em } \\
\text { Parceria } \\
\end{array}$ \\
\hline & Cervejaria responsável pela edição & Cervejarias Responsáveis Pela Edição \\
\hline \multirow{6}{*}{$\begin{array}{c}\text { ÁREA DE } \\
\text { PUBLICAÇÃO, } \\
\text { DISTRIBUIÇÃO ETC. }\end{array}$} & Lugar de produção & Local Da Cervejaria \\
\hline & Nome do produtor & $\begin{array}{c}\text { Nome Da Cervejaria Detentora Da } \\
\text { Receita }\end{array}$ \\
\hline & Data de produção & Data De Lançamento Do Rótulo \\
\hline & Nome do fabricante & $\begin{array}{c}\text { Cervejaria Responsável Pela } \\
\text { Fabricação } \\
\end{array}$ \\
\hline & Lugar de fabricação & $\begin{array}{c}\text { Local Da Cervejaria Responsável Pela } \\
\text { Fabricação } \\
\end{array}$ \\
\hline & Data de fabricação. & Data De Fabricação Da Amostra \\
\hline \multirow{5}{*}{$\begin{array}{c}\text { ÁREA DA } \\
\text { DESCRIÇÃO FISICA }\end{array}$} & $\begin{array}{c}\text { Extensão do item (incluindo } \\
\text { designação especifica do material) }\end{array}$ & $\begin{array}{l}\text { Quantidade Do Item: Designação Item: } \\
\text { Designação Do Contêiner }\end{array}$ \\
\hline & Dimensões & Volume Do Contêiner \\
\hline & Cor (srm) & $\begin{array}{c}\text { Nome Da Cor Ou Valor De Referência } \\
\text { De Acordo Com O Sem }\end{array}$ \\
\hline & $\mathrm{Ibu}$ & Unidade Internacional De Amargor \\
\hline & $\mathrm{Abv}$ & Álcool Por Volume, Teor Alcóolico \\
\hline \multirow{9}{*}{ ÁREA DAS NOTAS } & Tipo de cereal & \multirow{8}{*}{$\begin{array}{c}\text { Notas Referentes Aos Ingredientes Da } \\
\text { Cerveja }\end{array}$} \\
\hline & Tipo de malte & \\
\hline & Tipo de lúpulo & \\
\hline & Notas aromáticas & \\
\hline & Notas gustativas & \\
\hline & Tipo de levedura & \\
\hline & Tipo de fermentação & \\
\hline & Adjunto & \\
\hline & A região de origem da cerveja & $\begin{array}{c}\text { Notas Referentes A Região De Origem } \\
\text { Do Estilo Da Cerveja }\end{array}$ \\
\hline
\end{tabular}




\begin{tabular}{|c|c|c|}
\hline & $\begin{array}{c}\text { Era de produção (industrial, artesanal, } \\
\text { histórica) }\end{array}$ & $\begin{array}{c}\text { Notas Referentes Ao Método De } \\
\text { Produção Da Cerveja }\end{array}$ \\
\hline
\end{tabular}

Fonte: Elaboração do autor.

O Quadro 1 revelou a relação entre os elementos do Código de Catalogação com os elementos presentes na cerveja. O Quadro 2 apresenta quais elementos seriam considerados obrigatórios e opcionais que deverão estar presentes em um catálogo de cerveja.

Quadro 2 - Modelo de descrição para cervejas artesanais

\begin{tabular}{|c|c|c|}
\hline \multirow{3}{*}{$\begin{array}{l}\text { ÁREA DE TITULO E } \\
\text { INDICAÇÃO DE } \\
\text { RESPONSABILIDADE }\end{array}$} & Título da cerveja & Item Obrigatório \\
\hline & Designação geral do material & Item Obrigatório \\
\hline & Cervejaria responsável & Item Obrigatório \\
\hline \multirow{2}{*}{ ÁREA DA EDIÇÃO } & Indicação de edição & Item Opcional \\
\hline & Cervejaria responsável pela edição & Item Opcional \\
\hline \multirow{6}{*}{$\begin{array}{l}\text { ÁREA DE PUBLICAÇÃO, } \\
\text { DISTRIBUIÇÃO ETC. }\end{array}$} & Lugar de produção & Item Obrigatório \\
\hline & Nome do produtor & Item Obrigatório \\
\hline & Data de produção & Item Obrigatório \\
\hline & Nome do fabricante & Item Opcional \\
\hline & Lugar de fabricação & Item Opcional \\
\hline & Data de fabricação. & Item Opcional \\
\hline \multirow{5}{*}{ ÁREA DA DESCRIÇÃO FISICA } & $\begin{array}{c}\text { Extensão do item (incluindo } \\
\text { designação especifica do material) } \\
\end{array}$ & Item Obrigatório \\
\hline & Dimensões & Item Obrigatório \\
\hline & Cor $(\mathrm{srm})$ & Item Opcional \\
\hline & Ibu & Item Opcional \\
\hline & $\mathrm{Abv}$ & Item Opcional \\
\hline \multirow{10}{*}{ ÁREA DAS NOTAS } & Tipo de cereal & Item Opcional \\
\hline & Tipo de malte & Item Opcional \\
\hline & Tipo de lúpulo & Item Opcional \\
\hline & Notas aromáticas & Item Opcional \\
\hline & Notas gustativas & Item Opcional \\
\hline & Tipo de levedura & Item Opcional \\
\hline & Tipo de fermentação & Item Opcional \\
\hline & Adjunto & Item Opcional \\
\hline & A região de origem da cerveja & Item Opcional \\
\hline & $\begin{array}{c}\text { Era de produção (industrial, artesanal, } \\
\text { histórica) }\end{array}$ & Item Opcional \\
\hline
\end{tabular}

Fonte: Elaboração do autor.

\subsection{PROPOSTA DE UMA DESCRIÇÃO PARA CERVEJAS}

Com base no modelo resultante das discussões apresentadas na subseção 5.1, realizou-se a validação dos metadados. Para isso escolheu-se, aleatoriamente, quatro cervejas artesanais da cidade do Rio de
Janeiro, distribuídas em dois tipos de situações, denominadas em Caso 1: cervejas de mesmo estilo e Caso 2: cervejas com descrições extensas. Em cada caso foram analisadas duas cervejas, portanto o Caso 1 possui as cervejas $1 \mathrm{~A}$ e $1 \mathrm{~B}$; o Caso 2 possui as cervejas $2 \mathrm{~A}$ e $2 \mathrm{~B}$. $\mathrm{O}$ estudo sistematizado em dois casos, selecionados tendo em vista a 
especificidade, podem ser observados nos Quadros 3 a 8:

Figura 1 - Cervejas Jeffrey Niña e Cerveja Benja, El niño canibal.

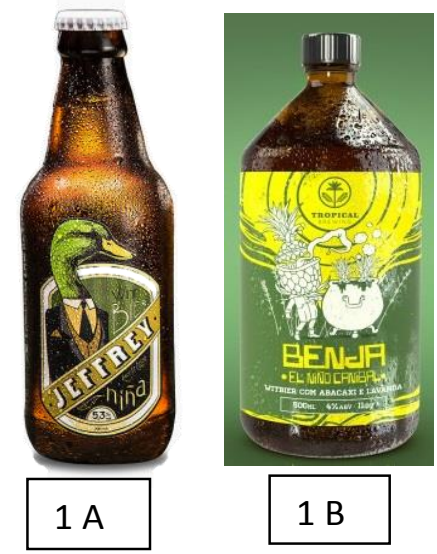

Fonte: Jeffrey (2015); Tropical (2015)

A cerveja 1A apresenta os seguintes metadados (adotou-se, para demarcar os elementos, a pontuação prescrita na ISBD):

Quadro 3 - Descrição da cerveja 1A

\begin{tabular}{|c|c|c|}
\hline \multirow{3}{*}{$\begin{array}{l}\text { ÁREA DE TITULO E } \\
\text { INDICAÇÃO DE } \\
\text { RESPONSABILIDADE }\end{array}$} & Título da cerveja & Niña \\
\hline & Designação geral do material & Cerveja: Ale: Witbier \\
\hline & Cervejaria responsável & Cervejaria Jeffrey \\
\hline \multirow{4}{*}{$\begin{array}{l}\text { ÁREA DE PUBLICAÇÃO, } \\
\text { DISTRIBUIÇÃO ETC. }\end{array}$} & Lugar de produção & Rio de Janeiro \\
\hline & Nome do produtor & Jeffrey \\
\hline & Lugar de fabricação & Rio de Janeiro \\
\hline & Nome do fabricante & Cervejaria Allegra \\
\hline \multirow{4}{*}{$\begin{array}{l}\text { ÁREA DA DESCRIÇÃO } \\
\text { FISICA }\end{array}$} & $\begin{array}{l}\text { Extensão do item (incluindo } \\
\text { designação especifica do material) }\end{array}$ & 1 Cerveja: Garrafa \\
\hline & Dimensões & $300 \mathrm{Ml}$ \\
\hline & Cor (srm) & Dourada \\
\hline & Abv & $5.3 \%$ \\
\hline \multirow{4}{*}{ ÁREA DAS NOTAS } & Tipo de cereal & Cevada; Trigo; Aveia \\
\hline & Adjunto & $\begin{array}{l}\text { Raspas de Limão Siciliano; } \\
\text { Semente de Coentro }\end{array}$ \\
\hline & A região de origem da cerveja & Bélgica \\
\hline & $\begin{array}{l}\text { Era de produção (industrial, artesanal, } \\
\text { histórica) }\end{array}$ & ARTESANAL \\
\hline
\end{tabular}

Fonte: Elaboração do autor.

A cerveja 1B apresenta os seguintes metadados (adotou-se, para demarcar os elementos, a pontuação prescrita na ISBD): 
Quadro 4 - Descrição da cerveja 1B

\begin{tabular}{|c|c|c|}
\hline \multirow{3}{*}{$\begin{array}{l}\text { ÁREA DE TITULO E } \\
\text { INDICAÇÃO DE } \\
\text { RESPONSABILIDADE }\end{array}$} & Título da cerveja & $\begin{array}{lll}\begin{array}{l}\text { Benja, } \\
\text { Canibal }\end{array} & \text { El Niño } \\
\end{array}$ \\
\hline & Designação geral do material & Cerveja: Ale: Witbier \\
\hline & Cervejaria responsável & Tropical Cervejaria \\
\hline \multirow{2}{*}{$\begin{array}{l}\text { ÁREA DE PUBLICAÇÃO, } \\
\text { DISTRIBUIÇÃO ETC. }\end{array}$} & Lugar de produção & Rio de Janeiro \\
\hline & Nome do produtor & Tropical Cervejaria \\
\hline \multirow{5}{*}{$\begin{array}{c}\text { ÁREA DA } \\
\text { DESCRIÇÃO FISICA }\end{array}$} & $\begin{array}{l}\text { Extensão do item (incluindo designação } \\
\text { especifica do material) }\end{array}$ & 1 Cerveja: Garrafa \\
\hline & Dimensões & $500 \mathrm{Ml}$ \\
\hline & Cor (srm) & Dourada \\
\hline & Ibu & 11 \\
\hline & $\mathrm{Abv}$ & $4 \%$ \\
\hline \multirow{3}{*}{ ÁREA DAS NOTAS } & Adjunto & Abacaxi; Lavanda \\
\hline & A região de origem da cerveja & Bélgica \\
\hline & $\begin{array}{l}\text { Era de produção (industrial, } \\
\text { artesanal, histórica) }\end{array}$ & Artesanal \\
\hline
\end{tabular}

Fonte: Elaboração do autor.

Figura 2 - Cerveja Funk IPA e cerveja Rio de Colônia

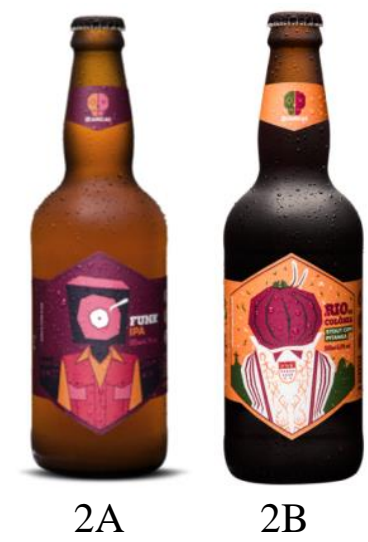

Fonte: 2 cabeças (2015)

A cerveja 2A apresenta os seguintes metadados (adotou-se, para demarcar os elementos, a pontuação prescrita na ISBD):

Quadro 5 - Descrição da cerveja 2A

\begin{tabular}{|c|c|l|}
\hline \multirow{2}{*}{$\begin{array}{c}\text { ÁREA DE TITULO E } \\
\text { INDICAÇÃO DE } \\
\text { RESPONSABILIDADE }\end{array}$} & Título da cerveja & Funk IPA \\
\cline { 2 - 3 } & Designação geral do material & $\begin{array}{l}\text { Cerveja: Ale: Session India Pale } \\
\text { Ale }\end{array}$ \\
\cline { 2 - 3 } & Cervejaria responsável & Cervejaria 2 Cabeças \\
\hline \multirow{2}{*}{$\begin{array}{c}\text { ÁREA DE PUBLICAÇÃO, } \\
\text { DISTRIBUIÇÃO ETC. }\end{array}$} & Lugar de produção & Rio de Janeiro \\
\cline { 2 - 3 } & Nome do produtor & Cervejaria 2 Cabeças \\
\hline
\end{tabular}




\begin{tabular}{|c|c|l|}
\hline \multirow{4}{*}{$\begin{array}{c}\text { ÁREA DA DESCRIÇÃO } \\
\text { FISICA }\end{array}$} & $\begin{array}{c}\text { Extensão do item (incluindo } \\
\text { designação especifica do material) }\end{array}$ & 1 Cerveja: Garrafa \\
\cline { 2 - 3 } & Dimensões & $500 \mathrm{ml}$ \\
\cline { 2 - 3 } & Cor (srm) & Dourada \\
\cline { 2 - 3 } & Ibu & 45 \\
\hline \multirow{4}{*}{ ÁREA DAS NOTAS } & Tipo de cereal & $4.7 \%$ \\
\cline { 2 - 3 } & Tipo de malte & Cevada \\
\cline { 2 - 3 } & Tipo de lúpulo & Zeus \\
\cline { 2 - 3 } & Notas aromáticas & Melão; Maracujá \\
\cline { 2 - 3 } & Adjunto & $\begin{array}{l}\text { Dry hopping: Zeus; Summit; } \\
\text { Amarillo }\end{array}$ \\
\cline { 2 - 3 } & A região de origem da cerveja & Estados Unidos \\
\cline { 2 - 3 } & Era de produção (industrial, artesanal, & Artesanal \\
\hline
\end{tabular}

Fonte: Elaboração do autor.

A cerveja 2B apresenta os seguintes metadados (adotou-se, para demarcar os elementos, a pontuação prescrita na ISBD):

Quadro 6 - Descrição da cerveja 2B

\begin{tabular}{|c|c|c|}
\hline \multirow{3}{*}{$\begin{array}{l}\text { Área De Título E } \\
\text { Indicação De } \\
\text { Responsabilidade }\end{array}$} & Título Da Cerveja & Rio De Colônia \\
\hline & Designação Geral Do Material & Cerveja: Ale: Fruit American Stout \\
\hline & Cervejaria Responsável & Cervejaria 2 Cabeças \\
\hline \multirow{3}{*}{ Área Da Edição } & Indicação De Edição & $\begin{array}{l}\text { Cerveja Colaborativa Entre A 2cabeças E } \\
\text { A Freigeist, Da Cidade De Colônia Na } \\
\text { Alemanha. }\end{array}$ \\
\hline & Cervejaria Responsável Pela Edição & Cervejaria 2 Cabeças \\
\hline & Cervejaria Responsável Pela Edição & Cervejaria Freigeist \\
\hline \multirow{2}{*}{$\begin{array}{l}\text { Área De Publicação, } \\
\text { Distribuição Etc. }\end{array}$} & Lugar De Produção & Rio de Janeiro \\
\hline & Nome Do Produtor & Cervejaria 2 Cabeças \\
\hline \multirow{5}{*}{$\begin{array}{l}\text { Área Da Descrição } \\
\text { Física }\end{array}$} & $\begin{array}{c}\text { Extensão Do Item (Incluindo } \\
\text { Designação Especifica Do Material) }\end{array}$ & 1 Cerveja: Garrafa \\
\hline & Dimensões & $500 \mathrm{Ml}$ \\
\hline & Cor (Srm) & Preta \\
\hline & $\mathrm{Ibu}$ & 50 \\
\hline & $\mathrm{Abv}$ & $6.0 \%$ \\
\hline \multirow{5}{*}{ Área Das Notas } & Tipo de Cereal & Cevada \\
\hline & Tipo de Malte & Malte Torrado \\
\hline & Adjunto & Pitanga; Flor de Sal \\
\hline & A Região De Origem Da Cerveja & Estados Unidos \\
\hline & $\begin{array}{l}\text { Era De Produção (Industrial, } \\
\text { Artesanal, Histórica). }\end{array}$ & Artesanal \\
\hline
\end{tabular}

Fonte: Elaboração do autor. 
Nos dois casos apresentados observa-se que os campos mais usados na descrição da cerveja artesanal são o título da cerveja, a designação geral do material, a cervejaria responsável, o lugar de produção, o nome do produtor, a extensão do item (incluindo designação específica do material), as dimensões, a cor (SRM), o ABV, o tipo de adjunto, a região de origem da cerveja, a era de produção (industrial, artesanal, histórica). Portanto deve-se levar em consideração neste estudo, que a coleta de dados foi feita através dos sites das cervejarias, ou seja, em nenhum momento o produto foi analisado em mãos. Em condições normais o catalogador tem o produto em mãos para análise e descrição, o que pode revelar novas informações relevantes para a descrição do objeto.

A partir da comparação dos resultados obtidos como os metadados definidos para a descrição da cerveja artesanal, observa-se que houve validação e pertinência dos metadados ao mesmo tempo em que atende as necessidades dos cervejeiros e consumidores quanto à representação e recuperação da informação sobre a cerveja artesanal.

Após analisar as regras do Código de catalogação Anglo-Americano (2002), as diretrizes dos guias de estilo de cerveja do Beer Judge Certification Program (2015) e do Brewers Association (2015) foram apurados metadados que atendessem as necessidades de descrição da cerveja. Como visto no breve histórico ao longo do tempo a cerveja se diferenciou devido aos processos e ingredientes diferentes, a cerveja se aprimorou e desenvolveu diversas características únicas e diferenciadores entre si. Por esse motivo foi desenvolvido como produto final desta pesquisa o modelo de descrição, baseado na representação descritiva, de cervejas artesanais.

\section{CONSIDERAÇÕES FINAIS}

Neste trabalho, foram identificados os elementos descritivos para a elaboração de uma catalogação de cervejas artesanais, com base nos princípios e fundamentos da Biblioteconomia, especialmente da
Catalogação utilizado da Representação descritiva. Sendo assim, apresentou-se o nosso objeto de estudo, a cerveja, desde sua criação, passando pela evolução e diferenciação dos processos e usos de ingredientes, assim como importantes descobertas, até os dias de hoje.

Essa contextualização permitiu compreender o objeto a ser catalogado. Em seguida foram discutidas as características da cerveja artesanal, seus ingredientes, métodos de produção.

Depois foi a vez de tratar a respeito das funções da catalogação, os objetivos de um catálogo e os elementos descritivos do recurso. Apresentaram-se os procedimentos utilizados para analisar os dados, e a própria análise dos dados, nesta seção foram elencados os elementos presentes na representação bibliográfica tradicional; identificaram-se quais elementos são necessários para se representar uma cerveja; foi proposto um modelo de descrição, com base na Biblioteconomia, para a representação de cervejas em catálogos.

Durante a pesquisa o maior desafio foi a falta de acesso ao objeto físico, sendo a análise feita somente através da imagem do rótulo disponibilizado nos sites das cervejarias. Chamando-nos a atenção para o fato que o acesso ao objeto poderá revelar novos elementos importantes para a descrição do objeto. O que revela a necessidade de estudos constantes e aprimoramentos futuros.

Constatou-se também que a literatura técnica referente às cervejas artesanais ainda é muito escassa o que acaba levando a repetição dos mesmos autores durante a revisão do referencial teórico. $\mathrm{O}$ método de classificação das cervejas tem seu embasamento em testes científicos, porém a catalogação das mesmas ainda é realizada de forma empírica, sendo então este trabalho relevante, pois validou os metadados para a descrição da cerveja artesanal, nosso objeto de estudo. Resultando na construção do modelo de catalogação que pode contribuir muito para o mercado cervejeiro, além de elucidar a atuação e contribuição do Bibliotecário em ambientes diferentes do tradicional. 


\title{
BEERS CATALOGUING CONTRIBUTIONS OF LIBRARIANSHIP TO THE DESCRIPTION OF RIO CRAFT BEER
}

\begin{abstract}
The research focuses on a standardized description for craft beers. As a general objective, it was sought to identify the descriptive elements for the elaboration of a description of the beers, based on the principles and foundations of Librarianship, especially of Cataloging. With a qualitative approach, we adopted the exploratory-descriptive method and the bibliographic and documentary research. The theory and instruments of organization and representation of information were analyzed. Data collection focused on the Rio de Janeiro artisanal beers, their containers, and information available on the brewery site. Documentary technical reading was carried out from a brewing perspective, from the brewery site and the cataloging instruments, metadata was elaborated from the identified elements, and the comparative analysis of the metadata indicated for the validation was used. In the results, it was reaffirmed the need to know the public informational demands for the description and, even more, the specialized technical knowledge of the document and the instruments of representation.
\end{abstract}

Keywords: Cataloguing. Craft beer. Rio craft beer. Descriptive representation.

\section{REFERÊNCIAS}

BARBOSA, Alice Príncipe. Novos Rumos da catalogação. Rio de Janeiro:

BNG/Brasilart, 1978.

BEAUMONT, Stephen; WEBB, TIM. Pocket beer book: the indispensable guide to the world's best craft and traditional beers.Great Britain: Mitchell Beazley, 2014.

\section{BEER JUDGE CERTIFICATION}

PROGRAM. Beer Style Guidelines. 2015.

Disponível em:

<http://www.bjcp.org/docs/2015 Guidelines

Beer.pdf $>$. Acesso em: 25 mar. 2015.

BELTRAMELLI, Mauricio. Cervejas, brejas e birras: um guia complete para desmistificar a bebida mais popular do brasil. São Paulo: Leya, 2014.

BREWERS ASSOCIATION. 2015 Beer

Style Guidelines. 18 fev. 2015. Disponível em: $<$ https://www.brewersassociation.org/wpcontent/uploads/2015/03/2015-brewersassociation-beer-style-guidelines.pdf $>$. Acesso em: 25 mar. 2015.

CAMPELLO, B. S. Introdução ao controle bibliográfico. 2. ed. Brasília: Briquet de Lemos, 2006.

CERVEJA JEFFREY. Disponível em: <https://www.facebook.com/cervejajeffrey/in fo/?tab=page info $>$. Acesso em: 13 out. 2015.

CERVEJARIA EDELBRAU. Cerveja Artesanal x Industrial. 13 fev. 2012. Disponível em: $\leq$ https://edelbrau.wordpress.com/2012/02/13/ce rveja-artesanal-x-industrial/>. Acesso em: 20 dez. 2015.

CERVEJAS. 2 Cabeças: repense cerveja. 2015. Disponível em: <http://www.2cabecas.com.br/cervejas/>. Acesso em: Acesso em: 11 out. 2015. 
CÓDIGO de catalogação anglo-americano. 2. ed. São Paulo: FEBAB, 2004.

\section{GRÁCIO, J. C. A. Metadados para a} descrição de recursos da Internet: o padrão Dublin Core, aplicações e a questão da interoperabilidade. Marília, 2002. 127p.

HAMPSON, Tim. O grande livro da cerveja: informações atualizadas sobre cervejas e as grandes cervejarias em todo o mundo. São Paulo: Publifolha, 2014.

HUGUES, Greg. Cerveja feita em casa: tudo sobre os ingredientes, os equipamentos e as técnicas para produzir a bebida em vários estilos. São Paulo: Publifolha, 2014.

INTERNATIONAL FEDERATION OF LIBRARY ASSOCIATIONS (IFLA). Declaração de princípios internacionais de catalogação. 2009. Disponível em:

<http://www.ifla.org/files/assets/cataloguing/i cp/icp_2009-pt.pdf $\rangle$. Acesso em: 3 set. 2015.

\section{INTERNATIONAL FEDERATION OF} LIBRARY ASSOCIATIONS (IFLA). International standard bibliographic description (ISBD): preliminary consolidated edition. 2007. Disponível em:

<http://www.ifla.org/files/assets/cataloguing/i sbd/isbd-cons_2007-en.pdf $>$. Acesso em: 3 sep. 2015.

JEFFREY. Disponível em:

$\langle$ http://jeffrey.com.br/page-beers. php〉. Acesso em: 14 out. 2015.

MEY, Eliane Serrão Alves. SILVEIRA, Naira Christofoletti. Catalogação no plural.

Brasília, DF: Briquet de Lemos, 2009.

MORADO, Ronaldo. Larousse da cerveja. São Paulo: Larousse do Brasil, 2009. ÖHLANDER, Johan. ÖHLANDER, Annika. 101 essential tips: home brewing. London: DK, 2015.

SANTOS, Rodrigo Eduardo dos; ZAFALON, Zaira Regina. Hot Wheels: catalogação e recuperação da informação em miniaturas de carros colecionáveis. En XII Congreso ISKO España y II Congreso ISKO España-Portugal, 19-20 de novembro, 2015, Organización del conocimiento para sistemas de información abiertos. Murcia: Universidad de Murcia.

SILVEIRA, Naira Christofoletti. Histórico da catalogação e do catálogo: apontamentos. Rio de Janeiro, 2013

TROPICAL CERVEJARIA. Disponível em: <https://www.facebook.com/tropicalcervejari a/photos stream>. Acesso em: 14 out. 2015. 